\title{
Efficacy of intravitreal dexamethasone implant for prostaglandin-induced refractory pseudophakic cystoid macular edema: case report and review of the literature
}

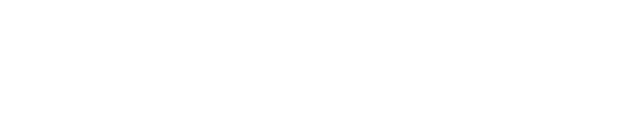

\author{
Matteo Sacchi \\ Edoardo Villani \\ Francesca Gilardoni \\ Paolo Nucci \\ University Eye Clinic, San Giuseppe \\ Hospital, University of Milan, \\ Milan, Italy
}

\begin{abstract}
Background: Macular edema is a known complication even after uneventful cataract surgery. The chronic use of prostaglandin analogs is a risk factor for the development of pseudophakic cystoid macular edema (CME). Nonsteroidal anti-inflammatory drugs (NSAIDs) are considered first-line therapy but refractory postsurgical CME represents a therapeutic challenge, as there is not an evidence-based treatment.
\end{abstract}

Objective: To report the use of a single implant of intravitreal dexamethasone for tafluprostassociated pseudophakic CME refractory to NSAIDs and to sub-Tenon's corticosteroid injections.

Case report: A 64-year-old female with ocular hypertension treated with tafluprost experienced decreased vision (visual acuity 20/60) and metamorphopsia 2 months after uneventful cataract extraction. Spectral domain optical coherence tomography (SD-OCT) revealed CME. After 1 month of topical and oral NSAIDs, CME was still evident on SD-OCT (visual acuity 20/50). Two sub-Tenon's betamethasone injections were performed at a 2-week interval. As CME was still present, 2 months after the diagnosis of CME (visual acuity 20/40), the patient underwent a single dexamethasone intravitreal implant. One month later, macular appearance was normal, and visual acuity increased to 20/30. This result was maintained throughout the 6 months of follow-up.

Conclusion: In this report, a single implant of intravitreal dexamethasone successfully treated pseudophakic CME associated with the use of prostaglandin analogs unresponsive to NSAIDs and sub-Tenon's betamethasone. The results of this report need to be corroborated by powered, prospective, randomized trials. The need for repeated treatments as well as the retreatment interval in patients requiring more than a single injection are issues still needing further investigations.

Keywords: prostaglandin-induced refractory cystoid macular edema, intravitreal dexamethasone implant, tafluprost, cataract surgery, pseudophakic cystoid macular edema

\section{Introduction}

Macular edema is a well-recognized complication of cataract surgery. Diabetic retinopathy, uveitis, chronic use of prostaglandin analogs (PGAs), and surgical complications are well-known risk factors for postsurgical cystoid macular edema (CME). ${ }^{1}$

Inflammation is considered the main etiologic factor in the pathogenesis of CME, and current evidence indicates that it depends on the breakdown of the bloodretinal membrane induced by the upregulation of inflammatory mediators, leading to increased vascular permeability and accumulation of fluid in the perifoveal retina. ${ }^{2}$
Correspondence: Matteo Sacchi University Eye Clinic, San Giuseppe Hospital, University of Milan, I2 Via San Vittore, Milan 20123, Italy

Tel +3902 85994975

Fax +3902 294I 5945

Email matteosacchi.hsg@gmail.com 
Topical nonsteroidal anti-inflammatory drugs (NSAIDs) and corticosteroids are considered first-line therapy for postsurgical $\mathrm{CME}{ }^{1}{ }^{2}$ however, in some patients $\mathrm{CME}$ does not resolve after medical therapy. These patients represent a challenge for the clinicians, as for refractory CME there is no standardized treatment, and although many approaches have been described, available therapies have showed conflicting results. ${ }^{1,2}$ Matsuura et al recently reported a case of tafluprost-associated pseudophakic CME successfully treated with a single sub-Tenon's triamcinolone injection. ${ }^{3}$ We present a case of tafluprost-associated pseudophakic CME refractory to NSAIDs and steroid sub-Tenon's injections successfully treated with a single intravitreal dexamethasone implant. This is the first report on the use of a dexamethasone implant for the treatment of prostaglandin-induced pseudophakic CME.

\section{Case}

A 64-year-old female Caucasian patient was referred to our hospital for decreased monocular vision and metamorphopsia. Her general history was unremarkable. Her ocular history revealed uneventful cataract surgery in her left eye approximately 2 months before the onset of symptoms. She had been taking tafluprost once a day for 1 year for ocular hypertension. Visual acuity (VA) was 20/60, +0.75. The anterior chamber was crystal clear, as was the posterior chamber intraocular lens. Intraocular pressure (IOP) was $16 \mathrm{mmHg}$. Fundoscopy and spectral domain optical coherence tomography (SD-OCT) revealed a CME with serous retinal detachment (SRD) (Figure 1A). Diagnosis was confirmed by fluorescein angiography. The fellow eye was healthy. The patient was treated with $0.3 \%$ nepafenac ophthalmic suspension (Nevanac ${ }^{\circledR}$; Alcon Laboratories,
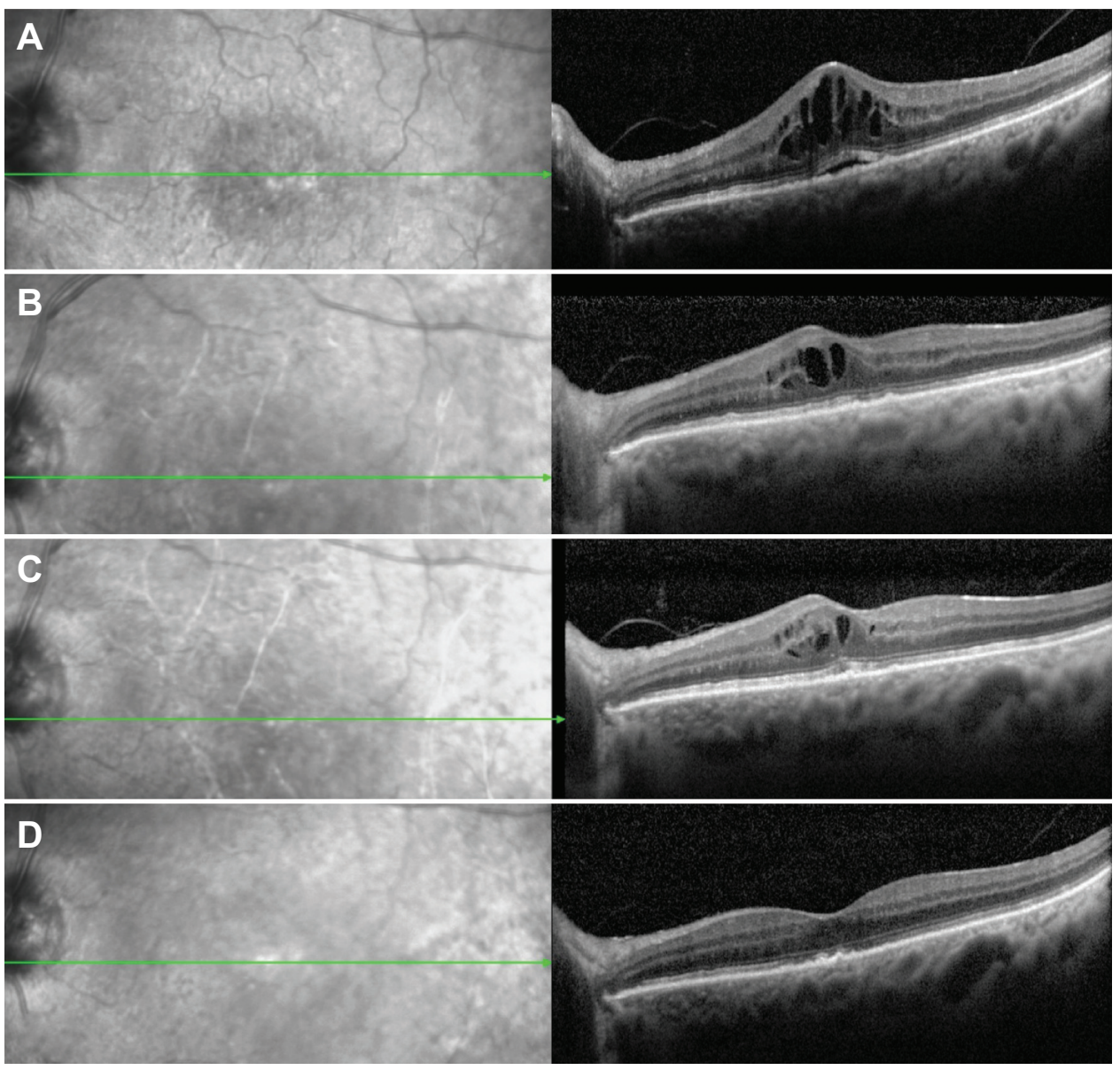

Figure I (A) Two months after cataract surgery, CME with SRD is shown on SD-OCT. NSAIDs therapy is started. (B) Month I: after I month of oral and topical NSAIDs, SRD disappeared, but CME was still evident on SD-OCT. Sub-Tenon's steroid injections are scheduled. (C) Month 2: after two consecutive injections of sub-Tenon's betamethasone CME is reduced, but still evident on SD-OCT. Intravitreal dexamethasone implant is scheduled. (D) Month 3 : after one intravitreal implant of $0.7 \mathrm{mg}$ dexamethasone, SD-OCT showed resolution of CME.

Abbreviations: CME, cystoid macular edema; SRD, serous retinal detachment; SD-OCT, spectral domain optical coherence tomography; NSAIDs, nonsteroidal antiinflammatory drugs. 
Fort Worth, TX, USA) four times a day for 1 month and indomethacin $50 \mathrm{mg}$ (Indoxen ${ }^{\circledR}$; Sigma-Tau, Rome, Italy) bid for 2 weeks. Tafluprost was discontinued and switched to timolol $0.50 \%$ twice a day. After 1 month of medical therapy, VA improved to 20/50 and SD-OCT showed resolution of the SRD; however, CME was still present (Figure 1B). Two sub-Tenon's injections of $4 \mathrm{mg}$ betamethasone were performed at 2-week intervals. One month after the first sub-Tenon's injection (2 months after the diagnosis of CME), VA was 20/40 and SD-OCT still showed CME (Figure 1C). At this time, we opted for an intravitreal $0.7 \mathrm{mg}$ dexamethasone implant (Ozurdex ${ }^{\circledR}$; Allergan, Irvine, CA, USA). The procedure was uneventful, and 1 month later VA improved to 20/30, with SD-OCT showing resolution of the CME (Figure 1D). These results were confirmed over 6 months of follow-up. IOP was between 16 and $24 \mathrm{mmHg}$ during the first month after the dexamethasone injection, and between 14 and $19 \mathrm{mmHg}$ throughout the follow-up.

\section{Discussion}

We report a case of refractory prostaglandin-induced pseudophakic CME. After 1 month of topical and systemic NSAIDs and two consecutive injections of sub-Tenon's steroid, CME was still evident on SD-OCT. Two months after the diagnosis of CME, a single intravitreal implant of dexamethasone effectively resolved the CME, improving visual acuity to 20/30. These results were stable over 6 months of follow-up.

PGAs are known risk factors for postsurgical CME. ${ }^{4}$ Tafluprost, the most recent PGA commercially available, has shown similar efficacy compared to other PGAs and a safe profile. ${ }^{5}$ To the best of our knowledge, this is the first report of the use of a dexamethasone implant for prostaglandininduced pseudophakic CME and the second case of pseudophakic CME associated with tafluprost. ${ }^{3}$ Several treatments have been described for pseudophakic CME, and although no standardized treatment exists, topical NSAIDs have become the mainstay of pseudophakic CME therapy and prophylaxis. Among the proposed approaches, the use of anti-VEGF has been suggested for the treatment of postsurgical CME, as VEGF is considered to play an important role in inflammation and in vascular permeability. ${ }^{1}$ However, studies exploring the efficacy of anti-VEGF for refractory pseudophakic CME have reported mixed findings. ${ }^{6-9}$

Corticosteroids are widely used in CME, due to their capability to control the inflammatory process involved in the development of macular edema. Corticosteroids can be delivered by topical, periocular, and subconjunctival routes.
Among them, the sub-Tenon's approach has been proven to achieve the highest vitreous levels, and has been shown to be effective for postsurgical CME in some ${ }^{3,10}$ but not all ${ }^{11}$ reports. Intravitreal injection of corticosteroids is also possible; however, evidence supporting this approach in pseudophakic $\mathrm{CME}$ is limited. In addition, the effect of the intravitreal injection of the drug is transient, needing multiple procedures with increased risk of endophathalmitis. ${ }^{1}$ Although there are studies showing that a single sub-Tenon's injection of triamcinolone successfully treated pseudophakic CME associated with tafluprost, travoprost, and latanoprost, ${ }^{3,12}$ in the current case and in a report by Brynskov et al ${ }^{11}$ sub-Tenon's injections of corticosteroids were not effective in resolving prostaglandin-induced CME. Because our case was unresponsive to topical NSAIDs and sub-Tenon's steroids, we opted for a dexamethasone implant. The sustained-release intravitreal dexamethasone implant has been proposed and has been proven to be effective for the treatment of CME arising from retinal vein occlusion and for the treatment of noninfectious uveitis affecting the posterior pole. ${ }^{13,14}$ Recently the efficacy of dexamethasone intravitreal implants has been reported even in recalcitrant cases of retinal vein-occlusion CME unresponsive to multiple intravitreal bevacizumab injections. ${ }^{15}$ The efficacy of the dexamethasone implant for refractory $\mathrm{CME}$ in retinal vein occlusion has encouraged its use even for postsurgical CME. Nowadays, the use of dexamethasone implants in refractory postsurgical CME is an emerging indication ${ }^{16}$ recently described in vitrectomized eyes $^{17}$ and after cataract extraction ${ }^{11,18-21}$ (Table 1). Some authors have suggested that an intravitreal implant of dexamethasone can be considered as first-line therapy for refractory postsurgical CME, among other intravitreally administered drugs. ${ }^{16,17}$ When corticosteroids are adopted, the route of administration is crucial for the efficacy of the therapy.

The use of intravitreal dexamethasone shows some advantages compared to the sub-Tenon's administration of steroids, which may explain the success of the former approach in the current case and in the study by Brynskov et al. ${ }^{11}$ First, the intravitreal route can achieve higher vitreous drug levels compared to the sub-Tenon's route. ${ }^{22}$ Second, whereas the subconjunctival route is associated with a short drug half-life, a sustained-release intravitreal dexamethasone implant allows a stabler and longer-lasting intravitreal delivery of the drug. ${ }^{16}$ In addition, the success of the dexamethasone implant compared to the use of other intravitreal steroids ${ }^{17,21}$ may be explained by the fact that dexamethasone is one of the most potent corticosteroids, showing, eg, anti-inflammatory activity sixfold higher than 
Table I Published studies on the use of dexamethasone implant for postsurgical cystoid macular edema

\begin{tabular}{|c|c|c|c|c|c|c|}
\hline Study & CME etiology & $\begin{array}{l}\text { Enrolled } \\
\text { patients }\end{array}$ & $\begin{array}{l}\text { Medical } \\
\text { therapy }\end{array}$ & $\begin{array}{l}\text { Periocular/ } \\
\text { IVT therapy }\end{array}$ & $\begin{array}{l}\text { Dexamethasone- } \\
\text { implant injections }\end{array}$ & Follow-up \\
\hline Williams et al $^{18}$ & Pseudophakic CME & 8 & $-{ }^{b}$ & - & I & 6 months \\
\hline Meyer and Schönfeld ${ }^{19}$ & Pseudophakic CME & I & - & $\begin{array}{l}3 \text { IVT dexamethasone } \\
(0.4 \mathrm{mg})\end{array}$ & I & 3 months \\
\hline Merkoudis and Granstam ${ }^{17}$ & Postsurgical $\mathrm{CME}^{\mathrm{a}}$ & 1 & $\begin{array}{l}\text { Topical NSAIDs } \\
\text { Topical steroids } \\
\text { Oral CAI }\end{array}$ & $\begin{array}{l}2 \text { IVT triamcinolone } \\
\text { I IVT ranibizumab }\end{array}$ & I & 10 months \\
\hline Brynskov et al' & Pseudophakic CME & 1 & - & $\begin{array}{l}\text { I ST triamcinolone } \\
5 \text { IVT ranibizumab }\end{array}$ & 2 & 6 months \\
\hline Furino et $\mathrm{al}^{20}$ & Pseudophakic CME & II & $\begin{array}{l}\text { Topical NSAIDs } \\
\text { Topical steroids }\end{array}$ & - & I & 6 months \\
\hline Dutra Medeiros et $\mathrm{al}^{21}$ & Pseudophakic CME & 9 & $\begin{array}{l}\text { Topical NSAIDs } \\
\text { Topical steroids } \\
\text { Oral CAI }\end{array}$ & $\begin{array}{l}\text { IVT anti-VEGF } \\
\text { IVT triamcinolone }\end{array}$ & I & 6 months \\
\hline Current report & Prostaglandin-induced CME & I & $\begin{array}{l}\text { Topical NSAIDs } \\
\text { Oral NSAIDs }\end{array}$ & 2 ST betamethasone & I & 6 months \\
\hline
\end{tabular}

Notes: ${ }^{a}$ Cataract and macular hole surgery; ${ }^{b}$ medical therapy not specified; use of systemic, periocular, or intraocular corticosteroids was prohibited within 30 days of enrollment; 'number of procedures not reported.

Abbreviations: CME, cystoid macular edema; IVT, intravitreal; ST, sub-Tenon's; CAI, carbonic anhydrase inhibitor; NSAIDs, nonsteroidal anti-inflammatory drugs.

triamcinolone.${ }^{16}$ Increases in IOP should be ruled out by close follow-up in any patients treated with dexamethasone implants, especially when dealing with patients affected by ocular hypertension or glaucoma; however, in our patient, IOP was well controlled, except in the first month after the intravitreal dexamethasone implant, when a mild, transient increase in IOP was reported.

\section{Conclusion}

We present the first case of prostaglandin-induced pseudophakic CME recalcitrant to NSAIDs and sub-Tenon's triamcinolone successfully treated by a single implant of intravitreal dexamethasone. Side effects were not reported, and the result was maintained throughout the 6-month follow-up.

Our case confirms the results of previous reports, and supports the emerging indication of dexamethasone implants for the treatment of refractory postsurgical CME. In addition, our results show that even in patients with ocular hypertension, an intravitreal dexamethasone implant can be used with a limited effect on IOP, although in such patients, close IOP control is mandatory.

Further powered, randomized, prospective studies with longer follow-up are warranted to corroborate this result and to elucidate the need for repeated treatments, as well as the retreatment interval in patients requiring more than a single injection.

\section{Disclosure}

The authors report no conflicts of interest in this work.

\section{References}

1. Yonekawa Y, Kim IK. Pseudophakic cystoid macular edema. Curr Opin Ophthalmol. 2012;23(1):26-32.

2. Arevalo JF, Maia M, Garcia-Amaris RA, et al. Intravitreal bevacizumab for refractory pseudophakic cystoid macular edema: the PanAmerican Collaborative Retina Study Group results. Ophthalmology. 2009;116(8):1481-1487.

3. Matsuura K, Uotani R, Terasaka Y. Subtenon triamcinolone injection for postoperative cystoid macular edema associated with tafluprost. Clin Ophthalmol. 2013;7:1525-1528.

4. Arcieri ES, Santana A, Rocha FN, Gaupo GL, Costa VP. Blood-aqueous barrier changes after the use of prostaglandin analogues in patients with pseudophakia and aphakia: a 6-month randomized trial. Arch Ophthalmol. 2005;123(2):186-192.

5. Ranno S, Sacchi M, Brancato C, Gilardi D, Lembo A, Nucci P. A prospective study evaluating IOP changes after switching from a therapy with prostaglandin eye drops containing preservatives to nonpreserved tafluprost in glaucoma patients. Scientific World Journal. 2012;2012:804730.

6. Barone A, Russo V, Prascina F, Delle Noci N. Short-term safety and efficacy of intravitreal bevacizumab for pseudophakic cystoid macular edema. Retina. 2009;29(1):33-37.

7. Demirel S, Batiolu F, Özmert E. Intravitreal ranibizumab for the treatment of cystoid macular edema in Irvine-Gass syndrome. J Ocul Pharmacol Ther. 2012;28(6):636-639.

8. Mason JO III, Albert MA Jr, Vail R. Intravitreal bevacizumab (Avastin) for refractory pseudophakic cystoid macular edema. Retina. 2006;26(3):356-357.

9. Spitzer MS, Ziemssen F, Yoeruek E, Petermeier K, Aisenbrey S, Szurman P. Efficacy of intravitreal bevacizumab in treating postoperative pseudophakic cystoid macular edema. J Cataract Refract Surg. 2008;34(1):70-75.

10. Randazzo A, Vinciguerra P. Chronic macular edema medical treatment in Irvine-Gass syndrome: case report. Eur J Ophthalmol. 2010; 20(2):462-465.

11. Brynskov T, Laugesen CS, Halborg J, Kemp H, Sørensen TL. Longstanding refractory pseudophakic cystoid macular edema resolved using intravitreal $0.7 \mathrm{mg}$ dexamethasone implants. Clin Ophthalmol. 2013;7:1171-1174.

12. Matsuura K, Sasaki S, Uotani R. Successful treatment of prostaglandininduced cystoid macular edema with subtenon triamcinolone. Clin Ophthalmol. 2012;6:2105-2108. 
13. Pichi F, Specchia C, Vitale L, et al. Combination therapy with dexamethasone intravitreal implant and macular grid laser in patients with branch retinal vein occlusion. Am J Ophthalmol. 2014;157(3): 607-615.

14. Haller JA, Bandello F, Belfort R Jr, et al. Randomized, shamcontrolled trial of dexamethasone intravitreal implant in patients with macular edema due to retinal vein occlusion. Ophthalmology. 2010;117(6):1134-1146.

15. Sharareh B, Gallemore R, Taban M, Onishi S, Wallsh J. Recalcitrant macular edema after intravitreal bevacizumab is responsive to an intravitreal dexamethasone implant in retinal vein occlusion. Retina. 2013;33(6):1227-1231.

16. Herrero-Vanrell R, Cardillo JA, Kuppermann BD. Clinical applications of the sustained-release dexamethasone implant for treatment of macular edema. Clin Ophthalmol. 2011;5:139-146.

17. Merkoudis N, Granstam E. Treatment of postoperative cystoid macular oedema with dexamethasone intravitreal implant in a vitrectomized eye - a case report. Acta Ophthalmol. 2013;91(3):e238-e239.
18. Williams GA, Haller JA, Kuppermann BD, et al. Dexamethasone posterior-segment drug delivery system in the treatment of macular edema resulting from uveitis or Irvine-Gass syndrome. Am J Ophthalmol. 2009;147(6):1048-1054.

19. Meyer LM, Schönfeld CL. Cystoid macular edema after complicated cataract surgery resolved by an intravitreal dexamethasone 0.7-mg implant. Case Rep Ophthalmol. 2011;2(3):319-322.

20. Furino C, Boscia F, Recchimurzo N, Sborgia C, Alessio G. Intravitreal dexamethasone implant for macular edema following uncomplicated phacoemulsification. Eur J Ophthalmol. 2014;24(3):387-391.

21. Dutra Medeiros M, Navarro R, Garcia-Arumí J, Mateo C, Corcóstegui B. Dexamethasone intravitreal implant for treatment of patients with recalcitrant macular edema resulting from Irvine-Gass syndrome. Invest Ophthalmol Vis Sci. 2013;54(5):3320-3324.

22. Inoue M, Takeda K, Morita K, Yamada M, Tanigawara Y, Oguchi Y. Vitreous concentrations of triamcinolone acetonide in human eyes after intravitreal or subtenon injection. Am J Ophthalmol. 2004;138(6):1046-1048.
Clinical Ophthalmology

\section{Publish your work in this journal}

Clinical Ophthalmology is an international, peer-reviewed journa covering all subspecialties within ophthalmology. Key topics include: Optometry; Visual science; Pharmacology and drug therapy in eye diseases; Basic Sciences; Primary and Secondary eye care; Patien Safety and Quality of Care Improvements. This journal is indexed on

Submit your manuscript here: http://www.dovepress.com/clinical-ophthalmology-journal

\section{Dovepress}

PubMed Central and CAS, and is the official journal of The Society of Clinical Ophthalmology (SCO). The manuscript management system is completely online and includes a very quick and fair peer-review system, which is all easy to use. Visit http://www.dovepress.com/ testimonials.php to read real quotes from published authors. 